\title{
Impact of Chronic Renal Failure on Safety and Effectiveness of Paclitaxel-Eluting Stents for Femoropopliteal Artery Disease: Subgroup Analysis from Zilver PTX Post-Market Surveillance Study in Japan
}

\author{
Yukihisa Ogawa $^{1} \cdot$ Hiroyoshi Yokoi $^{2} \cdot$ Takao Ohki $^{3} \cdot$ Kimihiko Kichikawa $^{4}$. \\ Masato Nakamura $^{5} \cdot$ Kimihiro Komori $^{6} \cdot$ Shinsuke Nanto $^{7}$ - Erin E. O'Leary ${ }^{8}$. \\ Aaron E. Lottes ${ }^{8} \cdot$ Alan T. Saunders $^{8} \cdot$ Michael D. Dake ${ }^{9}$
}

Received: 17 February 2017/ Accepted: 24 April 2017/Published online: 9 May 2017

(C) The Author(s) 2017. This article is an open access publication

\begin{abstract}
Purpose Favorable long-term outcomes of the Zilver PTX drug-eluting stent (DES) in femoropopliteal lesions have been demonstrated. Chronic renal failure (CRF) has been shown to be a risk factor for restenosis and decreased limb salvage. The results of the DES in patients with CRF have not previously been reported. This study compares the results with the DES in patients with CRF and those without CRF.

Methods This retrospective analysis from the Zilver PTX Japan Post-Market Surveillance Study included 321 patients with CRF and 584 patients without CRF.
\end{abstract}

Michael D. Dake

mddake@stanford.edu

1 Department of Radiology, St. Marianna University School of Medicine, Kawasaki, Japan

2 Department of Cardiovascular Medicine, Fukuoka Sanno Hospital, Fukuoka, Japan

3 Department of Surgery, Jikei University School of Medicine, Tokyo, Japan

4 Department of Radiology, Nara Medical University, Kashihara, Japan

5 Division of Cardiovascular Medicine, Ohashi Medical Center, Toho University, Tokyo, Japan

6 Division of Vascular Surgery, Department of Surgery, Nagoya University Graduate School of Medicine, Nagoya, Japan

7 Department of Cardiology, Nishinomiya Municipal Central Hospital, Nishinomiya, Japan

8 Cook Research Incorporated, West Lafayette, IN, USA

9 Department of Cardiothoracic Surgery, Falk Cardiovascular Research Center, Stanford University School of Medicine, 300 Pasteur Drive, Stanford, CA 94305-5407, USA
Outcomes included freedom from target lesion revascularization (TLR) and patency.

Results Of the patients included in this subgroup analysis, 2-year data were available for 209 patients in the CRF group and 453 patients in the non-CRF group. The two groups were similar in terms of lesion length and the frequency of in-stent restenosis. Critical limb ischemia, severe calcification, and diabetes were more common in patients with CRF, whereas total occlusion was more common in patients without CRF. Freedom from TLR rates were 81.4 versus $84.9 \%(p=0.24)$, and patency rates were 70.7 versus $70.3 \%(p=0.95)$ in patients with and without CRF at 2 years, respectively.

Conclusion This is the first comparative study of the DES in femoropopliteal artery lesions in patients with and without CRF. These results indicate that the DES placed in femoropopliteal artery lesions of CRF patients is safe and effective with similar patency and TLR rates to patients without CRF.

Level of Evidence Level 3, Post-Market Surveillance Study.

Keywords Drug-eluting stent · Paclitaxel-eluting stent $\cdot$ Peripheral artery disease $\cdot$ Femoropopliteal artery $\cdot$ Chronic renal failure

\section{Introduction}

Peripheral arterial disease (PAD) is commonly seen in patients with chronic renal failure (CRF) including dialysis $[1,2]$. Endovascular therapy is currently considered a first line of therapy for most cases of PAD when anatomically feasible [3]. There are many reports of bare metal stent (BMS) placement for treatment of patients with PAD 
involving the femoropopliteal (FP) arteries [3-6]. Throughout these experiences, CRF has been shown to be a significant risk factor for restenosis and decreased limb salvage $[4,5]$.

More recently, large clinical trials in patients with PAD have reported that a drug-eluting stent (DES) is able to reduce restenosis and provides superior long-term outcomes relative to BMS placement [7-11]. However, the effectiveness of the DES in PAD patients with CRF has not been established. The Zilver PTX Japan Post-Market Surveillance Study enrolled a large number of patients with CRF [12]. Taking advantage of this real-world population, a subgroup analysis compared the safety and effectiveness of the DES in patients with CRF to those without CRF.

\section{Methods}

\section{Study Design}

The current study is a subgroup analysis from the multicenter, prospective, single-arm Zilver PTX Post-Market Surveillance Study in Japan, with follow-up ongoing through 5 years [12]. The Zilver PTX DES (Cook Medical, Bloomington, IN) is a self-expanding nitinol stent with a polymer-free paclitaxel coating ( $3 \mu \mathrm{g} / \mathrm{mm}^{2}$ dose density). This study was required and regulated by the Japanese Ministry of Health, Labour, and Welfare, and informed consent processes were determined by each institution's ethical committee policy.

A detailed description of the DES, study design, indication for patient treatment, and statistical analysis has been previously reported [12].

\section{Patient Population}

A total of 905 patients with 1080 FP lesions were enrolled in this study between May 2012 and February 2013. Patients were divided into those with CRF, defined as an estimated glomerular filtration rate (eGFR) $<60 \mathrm{~mL} / \mathrm{min} /$ $1.73 \mathrm{~m}^{2}$ and/or dialysis ( $n=321$, CRF group), and those without CRF ( $n=584$, non-CRF group).

\section{Baseline Assessment, Intervention, and Medication}

Rutherford classification and ankle brachial index (ABI) were assessed pre-procedure. The device instructions for use recommend that the stent should be oversized by 1-2 $\mathrm{mm}$ with respect to the reference vessel and placed at least $1 \mathrm{~cm}$ below the superficial femoral artery origin and above the medial femoral epicondyle. Treatment of both legs was permitted. Pre- or post-dilatation and treatment of inflow or outflow disease were at the physician's discretion.
The same antiplatelet regimen described in previous studies was recommended for all patients [7-10]. In general, this included clopidogrel or ticlopidine starting at least $24 \mathrm{~h}$ before the procedure, or a procedural loading dose, continued clopidogrel or ticlopidine therapy for at least 60 days post-procedure, and aspirin indefinitely.

\section{Follow-Up Assessment}

Rutherford classification and ankle brachial index (ABI) were assessed at 1 year post-procedure.

Target lesion revascularization (TLR) was defined as reintervention performed for $\geq 50 \%$ diameter stenosis within $\pm 5 \mathrm{~mm}$ of the target lesion accompanied by recurrent clinical symptoms of PAD. Patency was assessed by duplex ultrasonography at 1 and 2 years where physicians considered this standard of care, with loss of patency corresponding to a peak systolic velocity ratio $\geq 2.4$.

Stent thrombosis was site-reported as total occlusion of suspected thrombotic origin. Stent integrity was evaluated by radiography at 1 year, with the next evaluations planned at 3 and 5 years. Clinical benefit was defined as freedom from persistent or worsening symptoms of ischemia (i.e., claudication, rest pain, ulcer, or tissue loss) after the initial study treatment. Amputation rate was also assessed during follow-up periods.

\section{Statistical Analysis}

The sample size of 900 was selected to provide $95 \%$ confidence for determination of events at rates as low as $1-2 \%$. Continuous variables were summarized with means \pm standard deviations, with $p$ values calculated using the standard $t$ test. Dichotomous and polytomous variables were reported as counts and percentages, with $p$ values calculated using the Fisher exact test. Rutherford $p$ values were calculated using the Cochran-Armitage test for trend. As appropriate, the number of observations represented the number of patients, treated lesions, and treated limbs. Kaplan-Meier analyses were used to assess freedom from TLR, freedom from thrombosis, clinical benefit, and patency over time, and log-rank test was used to compare the survival curves of the CRF and non-CRF groups. All data were analyzed using SAS software (version 9.3; SAS Institute, Inc, Cary, NC, USA).

\section{Results}

Of the 905 patients treated with the DES, 321 (35.5\%) patients were in the CRF group and 584 (64.5\%) patients were in the non-CRF group. Demographics and lesion 
Table 1 Patient demographics and lesion characteristics

\begin{tabular}{|c|c|c|c|}
\hline & $\mathrm{CRF}$ & Non-CRF & $p$ value \\
\hline Patient, $N$ & 321 & 584 & - \\
\hline Age & $72.1 \pm 8.8$ & $74.2 \pm 8.2(584)$ & $<0.001$ \\
\hline Male & $67.9(218)$ & $71.6(418)$ & 0.25 \\
\hline Diabetes & $69.2(222)$ & $53.1(310)$ & $<0.001$ \\
\hline Hypertension & $85.7(275)$ & $85.3(498)$ & 0.92 \\
\hline Hypercholesterolemia & $56.7(182)$ & $63.0(368)$ & 0.06 \\
\hline Pulmonary disease & $5.9(19)$ & $9.2(54)$ & 0.10 \\
\hline Lesions, $N$ & 381 & 699 & - \\
\hline Lesion length (mm) & $145.8 \pm 93.1(381)$ & $147.3 \pm 98.2(698)$ & 0.8 \\
\hline Total occlusion & $34.4(131)$ & $45.4(317)$ & $<0.001$ \\
\hline In-stent restenosis & $16.8(64)$ & $19.6(137)$ & 0.26 \\
\hline$\%$ diameter stenosis & $91.3 \pm 10.4(381)$ & $92 \pm 11.1(699)$ & 0.29 \\
\hline \multicolumn{4}{|l|}{ Calcification } \\
\hline None & $14.2(54)$ & $33.6(235)$ & \multirow[t]{4}{*}{$<0.001$} \\
\hline Mild & $28.9(110)$ & $37.6(263)$ & \\
\hline Moderate & $24.7(94)$ & $19.6(137)$ & \\
\hline Severe & $32.3(123)$ & $9.2(64)$ & \\
\hline \multicolumn{4}{|l|}{ Rutherford $^{\mathrm{a}}$} \\
\hline 0 & $1.1(4)$ & $0.9(6)$ & \multirow[t]{7}{*}{$<0.001$} \\
\hline 1 & $6.3(23)$ & $7.8(51)$ & \\
\hline 2 & $19.3(70)$ & $30.6(201)$ & \\
\hline 3 & $39.9(145)$ & $46.0(302)$ & \\
\hline 4 & $13.5(49)$ & $8.5(56)$ & \\
\hline 5 & $17.4(63)$ & $5.5(36)$ & \\
\hline 6 & $2.5(9)$ & $0.8(5)$ & \\
\hline \multicolumn{4}{|l|}{ Runoff vessels ${ }^{b}$} \\
\hline 0 & $6.9(26)$ & $6.5(45)$ & \multirow[t]{3}{*}{0.19} \\
\hline 1 & $35.3(133)$ & $30.1(210)$ & \\
\hline$\geq 2$ & $57.8(218)$ & $63.4(442)$ & \\
\hline $\mathrm{ABI}$ & $0.63 \pm 0.21$ & $0.63 \pm 0.16(641)$ & 0.69 \\
\hline
\end{tabular}

Values are mean $\pm \mathrm{SD}$ or $\%(n)$

$A B I$ ankle brachial index

${ }^{a}$ Rutherford classification data not available for 18 lesions in the CRF group and for 60 lesions in the nonCRF group

b Runoff vessel data not available for four lesions in the CRF group and two lesions in the non-CRF group characteristics are shown in Table 1. Diabetes, critical limb ischemia, calcification, and reduced runoff were more frequently seen in the CRF group. In contrast, total occlusions were more prevalent in the non-CRF group. Other comorbidities and lesion characteristics including pre-procedure ABI, mean lesion length $(145.8 \pm 93.1$ and $147.3 \pm 98.2 \mathrm{~mm}$ ), and the existence of in-stent restenosis were not significantly different between CRF group and non-CRF group, respectively. Of the 224 patients in the CRF group and 486 patients in the non-CRF group eligible for 2-year follow-up, data were available for 209 (93.3\%) and $453(93.2 \%)$ patients, respectively (Fig. 1).

\section{Safety}

There were no device- or procedure-related deaths. Allcause mortality through 2 years was $18 \%$ in the CRF group and $6 \%$ in the non-CRF group $(p<0.01)$. No paclitaxelrelated adverse events were observed. A total of 1249 DES were implanted (438 in the CRF group and 811 in the nonCRF group). There were no perioperative stent fractures. At 1 year, one stent fracture $(0.5 \%)$ was observed in the CRF group and 16 fractures $(3.7 \%)$ in the non-CRF group $(p=0.016)$. As shown in Table 2 , there were no significant differences in freedom from TLR or thrombosis 


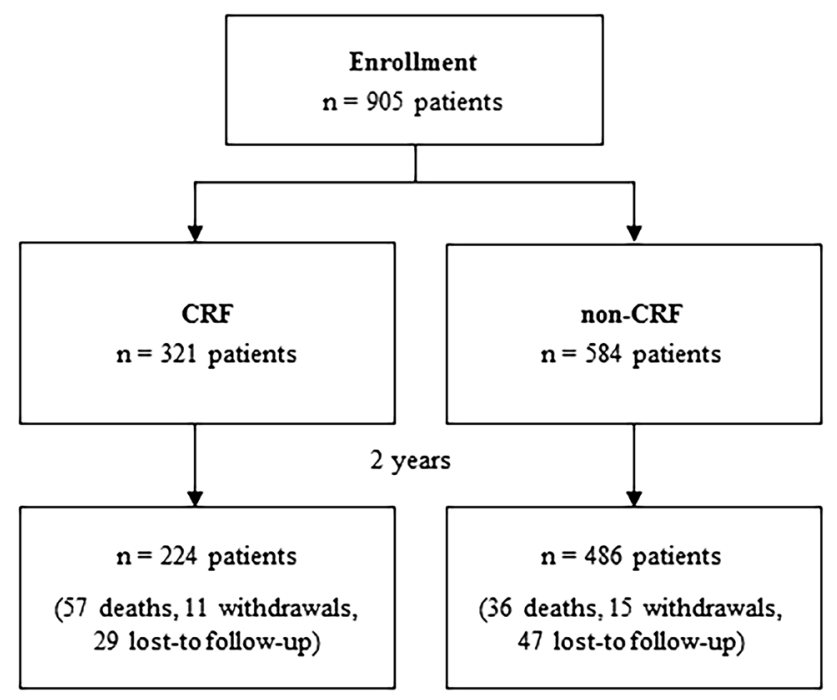

Fig. 1 Patient flowchart. Of the 905 patients enrolled in the study, 321 patients were in the CRF group and 584 patients were in the nonCRF group. At 2 years, 224 patients in the CRF group and 486 patients in the non-CRF group remained in the study; death (all-cause), withdrawals, and lost to follow-up through 2 years are shown

through 2 years. A Kaplan-Meier curve for freedom from TLR is provided in Fig. 2, with 2-year rates of $81.4 \%$ for the CRF group and $84.9 \%$ for the non-CRF group $(p=0.24$ log-rank). Through 2 years, eight patients $(2.5 \%)$ in the CRF group and two patients $(0.3 \%)$ in the non-CRF group had an amputation $(p=0.005)$. Of these, six patients in the CRF group and both patients in the nonCRF group had a pre-procedure Rutherford classification of five. Additionally, three amputations in the CRF group and one amputation in the non-CRF group occurred within 2 months from the intervention.

\section{Patency and Clinical Outcomes}

Patency and clinical benefit results through 2 years are presented in Table 2. There were no significant differences in patency between the CRF and non-CRF groups through 2 years (70.7 versus $70.3 \%, p=0.95$ log-rank). The clinical benefit rates were similar in the CRF and non-CRF groups through 1 year; however, through 2 years, the rate in the CRF group was lower compared to the non-CRF group (74.1 versus $82.5 \%, p<0.01$ log-rank). KaplanMeier curves are provided in Figs. 3 and 4. As shown in Table 2, ABI improved in both groups from pre-procedure through 1 and 2 years. In addition, overall Rutherford classification improved and the incidence of CLI was reduced through 1 and 2 years in both groups (Fig. 5).

\section{Discussion}

The present study demonstrates the safety and effectiveness of the DES for treatment of FP lesions in patients with CRF. To the best of our knowledge, this is the first comparative study of the DES for FP lesions between CRF and non-CRF groups.

Traditionally, CRF is considered a high-risk factor for restenosis, with twice the incidence of restenosis in CRF patients undergoing hemodialysis [5], and decreased limb

Table 2 Study outcomes

\begin{tabular}{|c|c|c|c|c|}
\hline Outcome & Time & $\mathrm{CRF}$ & Non-CRF & $p$ value \\
\hline Stent fracture & 1-year & $0.5 \%(1 / 216)$ & $3.7 \%(16 / 434)$ & 0.016 \\
\hline \multirow[t]{2}{*}{ Freedom from TLR } & 1-year & $91.5 \%$ & $90.8 \%$ & \multirow[t]{2}{*}{$0.24^{\mathrm{a}}$} \\
\hline & 2-years & $81.4 \%$ & $84.9 \%$ & \\
\hline \multirow[t]{2}{*}{ Freedom from thrombosis } & 1-year & $96.9 \%$ & $96.6 \%$ & \multirow[t]{2}{*}{$0.46^{\mathrm{a}}$} \\
\hline & 2-years & $95.1 \%$ & $96.3 \%$ & \\
\hline \multirow[t]{2}{*}{ Amputation $^{\mathrm{b}}$} & 1-year & $2.2 \%(7 / 321)$ & $0.3 \%(2 / 584)$ & 0.01 \\
\hline & 2-years & $2.5 \%(8 / 321)$ & $0.3 \%(2 / 584)$ & 0.005 \\
\hline \multirow[t]{2}{*}{ Patency } & 1-year & $88.6 \%$ & $84.2 \%$ & \multirow[t]{2}{*}{$0.95^{\mathrm{a}}$} \\
\hline & 2-years & $70.7 \%$ & $70.3 \%$ & \\
\hline \multirow[t]{2}{*}{ Clinical benefit } & 1 -year & $87.1 \%$ & $89.7 \%$ & \multirow[t]{2}{*}{$<0.01^{\mathrm{a}}$} \\
\hline & 2-years & $74.1 \%$ & $82.5 \%$ & \\
\hline \multirow[t]{2}{*}{$\mathrm{ABI}$} & 1-year* & $0.85 \pm 0.18$ & $0.86 \pm 0.16$ & 0.41 \\
\hline & 2 -years* & $0.84 \pm 0.21$ & $0.85 \pm 0.17$ & 0.41 \\
\hline \multicolumn{5}{|c|}{$T L R$ target lesion revascularization and $A B I$ ankle brachial index } \\
\hline \multicolumn{5}{|c|}{ *Statistically significant compared to pre-procedure, $p<0.01$} \\
\hline \multicolumn{5}{|c|}{${ }^{a}$ Log-rank $p$ values comparing the two groups over time (i.e., from pre-procedure through 2 years) } \\
\hline
\end{tabular}


Fig. 2 Freedom from TLR. Kaplan-Meier curves of freedom from clinically driven target lesion revascularization (TLR) for patients in the nonCRF group (black line) versus patients in the CRF group (red line). Freedom from TLR was $84.9 \%$ in the non-CRF group versus $81.4 \%$ in the CRF group through 2 years $(p=0.24, \log$ rank test)

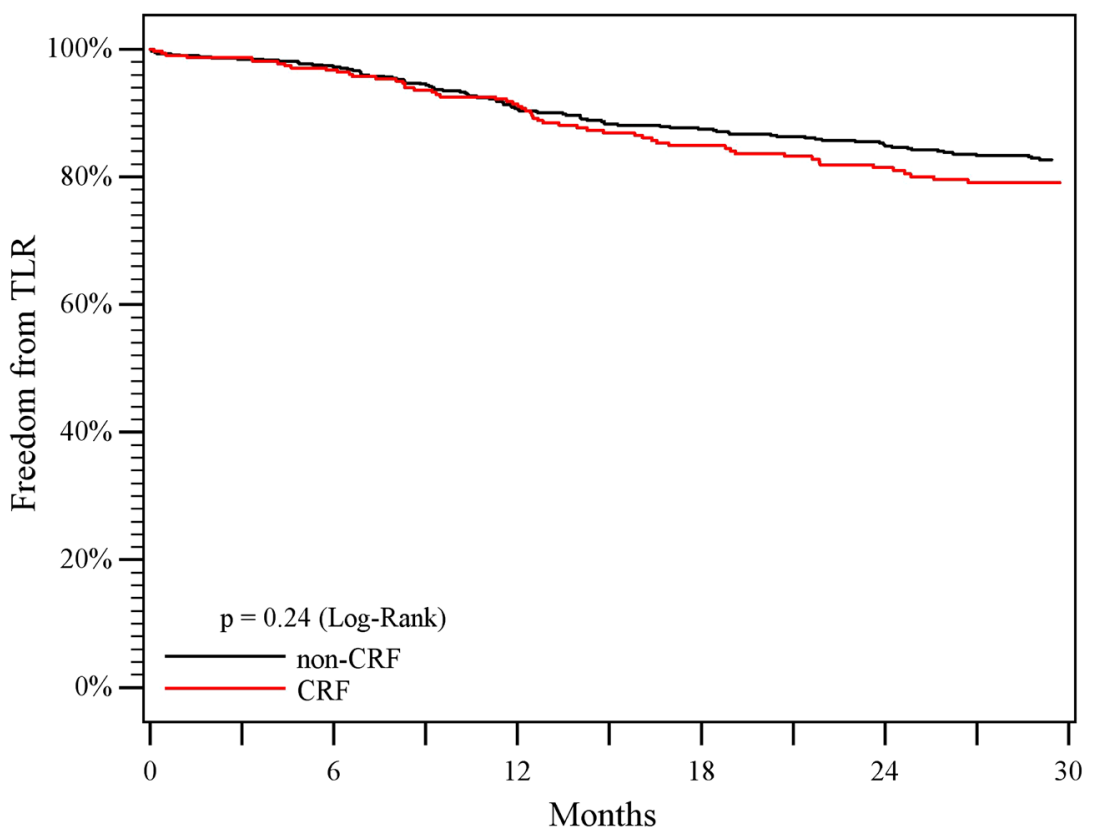

\begin{tabular}{|c|c|c|c|c|c|c|c|c}
\hline \multicolumn{1}{c|}{ Kaplan-Meier Estimates for Freedom from TLR, Values Represent Patients } \\
\hline $\begin{array}{c}\text { Months } \\
\text { Post- } \\
\text { procedure }\end{array}$ & \multicolumn{2}{|c|}{$\begin{array}{c}\text { Freedom from } \\
\text { TLR }\end{array}$} & \multicolumn{2}{c|}{$\begin{array}{c}\text { Cumulative } \\
\text { Failed }\end{array}$} & \multicolumn{2}{c|}{$\begin{array}{c}\text { Cumulative } \\
\text { Censored }\end{array}$} & \multicolumn{2}{c}{$\begin{array}{c}\text { Number } \\
\text { Remaining }\end{array}$} \\
\cline { 2 - 9 } & CRF & $\begin{array}{c}\text { Non- } \\
\text { CRF }\end{array}$ & CRF & $\begin{array}{c}\text { Non- } \\
\text { CRF }\end{array}$ & CRF & $\begin{array}{c}\text { Non- } \\
\text { CRF }\end{array}$ & CRF & $\begin{array}{c}\text { Non- } \\
\text { CRF }\end{array}$ \\
\hline 0 & $\begin{array}{c}100 \% \pm \\
0.0 \%\end{array}$ & $\begin{array}{c}100 \% \pm \\
0.0 \%\end{array}$ & 0 & 0 & 0 & 0 & 321 & 583 \\
\hline 12 & $\begin{array}{c}91.5 \% \pm \\
1.7 \%\end{array}$ & $\begin{array}{c}90.8 \% \pm \\
1.2 \%\end{array}$ & 25 & 52 & 49 & 34 & 247 & 497 \\
\hline 24 & $\begin{array}{c}81.4 \% \pm \\
2.6 \%\end{array}$ & $\begin{array}{c}84.9 \% \pm \\
1.6 \%\end{array}$ & 50 & 82 & 94 & 96 & 177 & 405 \\
\hline
\end{tabular}

salvage after endovascular therapy, with twice the rate of amputation in patients with severe CRF compared to patients with mild and moderate CRF [4]. CRF is commonly associated with PAD lesions that are more severely calcified and diffuse than those observed in patients without CRF [4, 5]. Pathologically, increased chronic inflammation is typically noted in the peripheral arteries of patients with CRF compared to the vessels of non-CRF patients with PAD. Furthermore, CRF patients are frequently on dialysis, which results in platelet dysfunction and may activate plasma coagulation factors that can cause restenosis due to resultant mural thrombosis [13-15].

CRF has also been identified as a risk factor for mortality in patients with PAD [2]. In the current study, mortality rates were three times higher in the CRF group compared to the non-CRF group. This is consistent with previous studies where the mortality rates have been reported as $13 \%$ for patients with mild CRF and $41 \%$ for patients with severe CRF [4].
In the present study, diabetes, critical limb ischemia, calcification, and reduced runoff were more frequently seen in the CRF group, and total occlusions were more prevalent in the non-CRF group. Contrary to traditional expectations and despite the differences in demographics and lesion characteristics, there were no significant differences in stent patency, TLR, and thrombosis between the CRF and non-CRF groups. Some previous BMS studies also demonstrated that stent patency was not affected by the presence of CRF [16-19]. However, these studies included only a small number of patients with renal failure. The results with drug-coated balloons in CRF patients have not been previously reported. The 2-year freedom from TLR rate in the CRF group was $81.4 \%$, compared to $86.0 \%$ in the Zilver PTX Randomized Clinical Trial [9]. The 2-year stent patency rate was $70.7 \%$ in the CRF group compared to $74.8 \%$ in the Zilver PTX Randomized Clinical Trial [8]. One explanation for these differences could be that the CRF patients had a greater frequency of CLI and longer 
Fig. 3 Primary patency. Kaplan-Meier curves of primary patency for patients in the non-CRF group (black line) versus patients in the CRF group (red line). Primary patency was $70.3 \%$ in the nonCRF group versus $70.7 \%$ in the CRF group through 2 years $(p=0.95$, log-rank test $)$

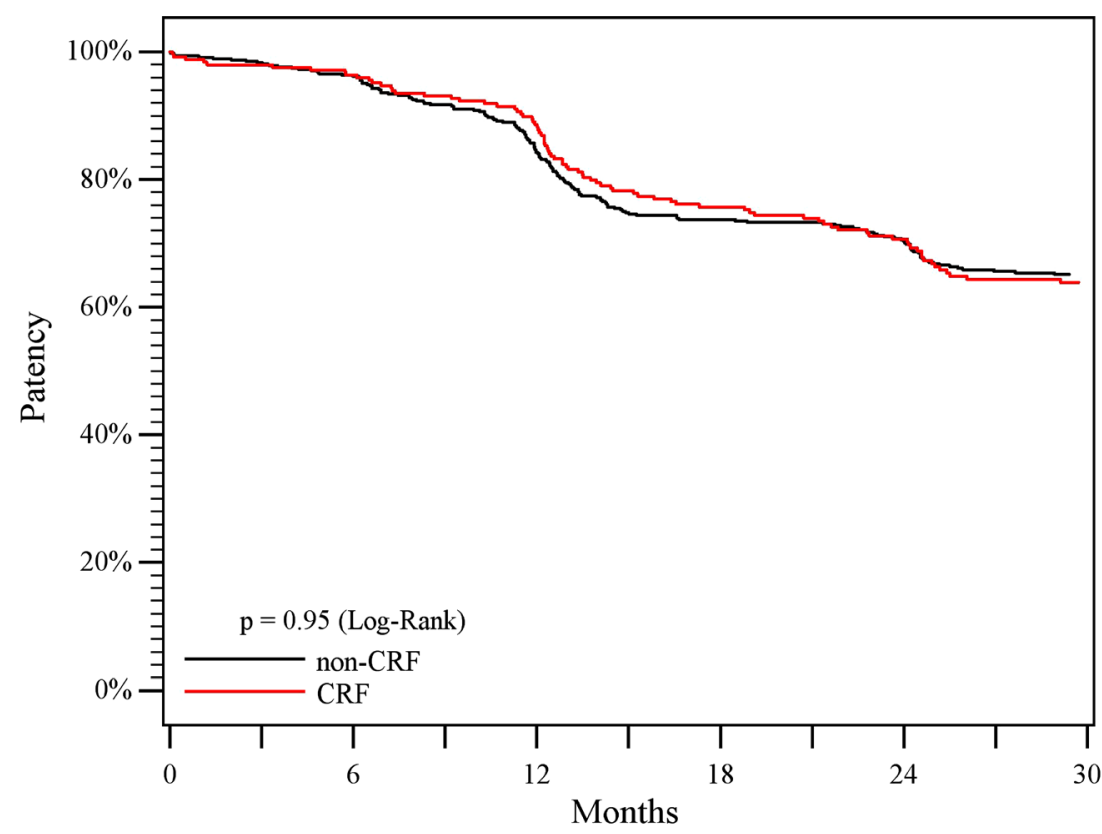

\begin{tabular}{|c|c|c|c|c|c|c|c|c|}
\hline \multicolumn{6}{|c|}{ Kaplan-Meier Estimates for Primary Patency, Values Represent Lesions } \\
\hline $\begin{array}{c}\text { Months } \\
\text { Post- } \\
\text { procedure }\end{array}$ & $\begin{array}{c}\text { Primary Patency } \\
\pm \text { Standard Error }\end{array}$ & \multicolumn{2}{|c|}{$\begin{array}{c}\text { Cumulative } \\
\text { Failed }\end{array}$} & \multicolumn{2}{c|}{$\begin{array}{c}\text { Cumulative } \\
\text { Censored }\end{array}$} & \multicolumn{2}{c|}{$\begin{array}{c}\text { Number } \\
\text { Remaining }\end{array}$} \\
\cline { 2 - 9 } & CRF & $\begin{array}{c}\text { Non- } \\
\text { CRF }\end{array}$ & CRF & $\begin{array}{c}\text { Non- } \\
\text { CRF }\end{array}$ & CRF & $\begin{array}{c}\text { Non- } \\
\text { CRF }\end{array}$ & CRF & $\begin{array}{c}\text { Non- } \\
\text { CRF }\end{array}$ \\
\hline 0 & $\begin{array}{c}100 \% \pm \\
0.0 \%\end{array}$ & $\begin{array}{c}100 \% \pm \\
0.0 \%\end{array}$ & 0 & 0 & 0 & 0 & 247 & 470 \\
\hline 12 & $\begin{array}{c}88.6 \% \pm \\
2.0 \%\end{array}$ & $\begin{array}{c}84.2 \% \pm \\
1.7 \%\end{array}$ & 28 & 74 & 4 & 1 & 215 & 395 \\
\hline 24 & $\begin{array}{c}70.7 \% \pm \\
3.1 \%\end{array}$ & $\begin{array}{c}70.3 \% \pm \\
2.1 \%\end{array}$ & 70 & 138 & 29 & 29 & 148 & 303 \\
\hline
\end{tabular}

lesion lengths-over twice as long-when compared to what was reported in patients enrolled in other studies with this DES.

Despite no significant difference in stent patency or TLR between the two groups, the clinical benefit in the CRF group decreased around 1 year relative to the non-CRF group, primarily due to claudication and rest pain in the CRF group. Also, the 2-year clinical benefit rate in the CRF group $(74.1 \%)$ was lower than the published rate of $81.8 \%$ for Zilver PTX in the Randomized Clinical Trial [8]. The relatively lower clinical benefit in CRF patients may be due to the nature of their underlying disease with poor tibial runoff and/or severe calcification, which could progress to a worsening clinical condition and Rutherford classification. Additional factors that accompany CRF, but are not related to stent performance, including malnutrition, nonhealing advanced tissue loss, and immunologic dysfunction [4, 20, 21], likely also contribute to reduced clinical benefit. Many previous BMS studies have also shown the deleterious effect of CRF on clinical outcomes $[1,3,4,17,19,22]$.
Nearly all amputations occurred in patients with preprocedure Rutherford classification of five. Additionally, three amputations in CRF patients, all with pre-procedure Rutherford classification of five, occurred within the first 2 months following DES placement, even though the stents remained patent through this time. This likely reflects the complex nature of CRF and a more advanced stage of PAD at the time of treatment, which may have resulted in a preprocedure expectation of planned distal amputation. Although the 2-year rate of amputation in the CRF group $(2.5 \%)$ was statistically higher than that observed in the non-CRF group $(0.3 \%)$, these rates were both lower than the 5-28\% amputation rates reported in previous BMS studies [4, 5, 18, 23]. In some surgical bypass studies, approximately half of patients with severe CRF required amputation despite patent bypass grafts because of the complex nature of $\mathrm{CRF}$ and high frequency of CLI $[24,25]$.

Also of note, CLI was reduced after DES placement in CRF patients to approximately one-fourth the pre-procedure frequency in the present study. Thus, DES treatment 
Fig. 4 Post-treatment clinical benefit. Clinical benefit was defined as freedom from persistent or worsening symptoms of ischemia (i.e., claudication, rest pain, ulcer, or tissue loss) after the initial study treatment. Kaplan-Meier curves of clinical benefit for patients in the non-CRF group (black line) versus patients in the CRF group (red line). Clinical benefit was $82.5 \%$ in the non-CRF group versus $74.1 \%$ in the CRF group through 2 years $(p<0.01$, log-rank test $)$

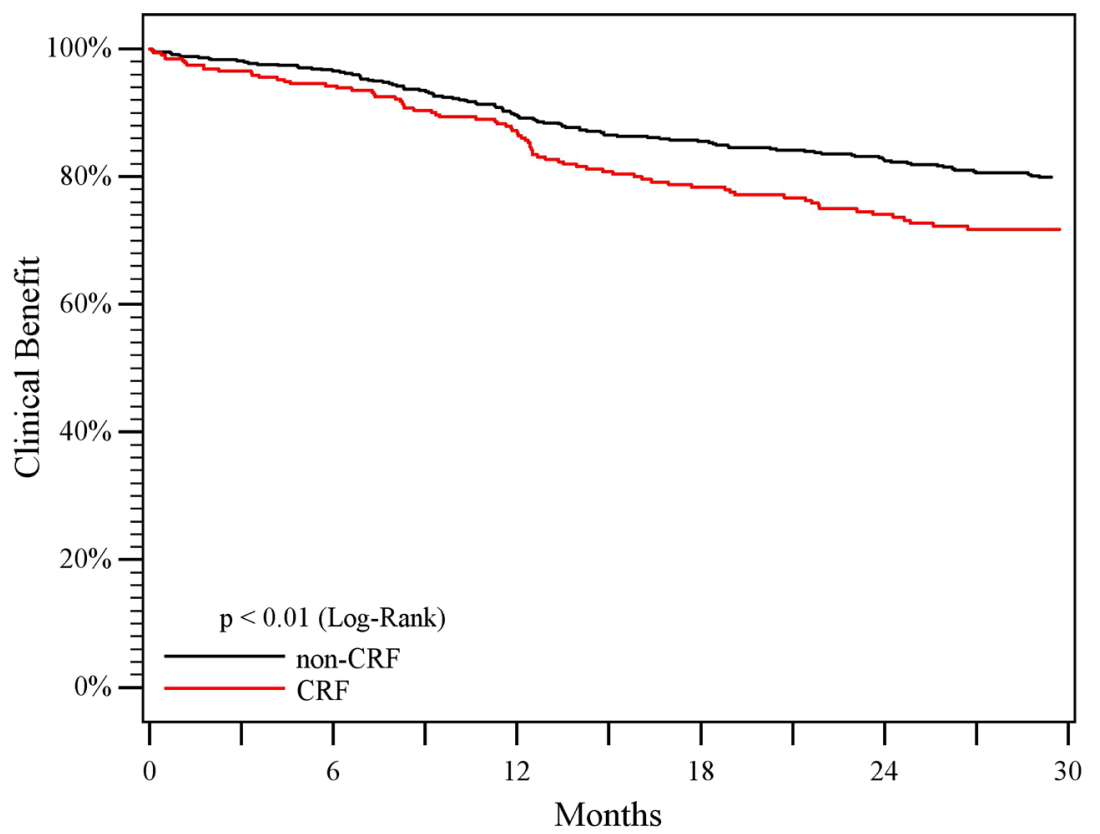

\begin{tabular}{|c|c|c|c|c|c|c|c|c|}
\hline \multicolumn{1}{|c|}{ Kaplan-Meier Estimates for Clinical Benefit, Values Represent Patients } \\
\hline $\begin{array}{c}\text { Months } \\
\text { Post- } \\
\text { procedure }\end{array}$ & $\begin{array}{c}\text { Clinical Benefit } \\
\pm \text { Standard Error }\end{array}$ & \multicolumn{2}{|c|}{$\begin{array}{c}\text { Cumulative } \\
\text { Failed }\end{array}$} & \multicolumn{2}{c|}{$\begin{array}{c}\text { Cumulative } \\
\text { Censored }\end{array}$} & \multicolumn{2}{c}{$\begin{array}{c}\text { Number } \\
\text { Remaining }\end{array}$} \\
\cline { 2 - 9 } & CRF & $\begin{array}{c}\text { Non- } \\
\text { CRF }\end{array}$ & CRF & $\begin{array}{c}\text { Non- } \\
\text { CRF }\end{array}$ & CRF & $\begin{array}{c}\text { Non- } \\
\text { CRF }\end{array}$ & CRF & $\begin{array}{c}\text { Non- } \\
\text { CRF }\end{array}$ \\
\hline 0 & $\begin{array}{c}100 \% \pm \\
0.0 \%\end{array}$ & $\begin{array}{c}100 \% \pm \\
0.0 \%\end{array}$ & 0 & 0 & 0 & 0 & 321 & 583 \\
\hline 12 & $\begin{array}{c}87.1 \% \pm \\
2.0 \%\end{array}$ & $\begin{array}{c}89.7 \% \pm \\
1.3 \%\end{array}$ & 38 & 58 & 46 & 33 & 237 & 492 \\
\hline 24 & $\begin{array}{c}74.1 \% \pm \\
2.9 \%\end{array}$ & $\begin{array}{c}82.5 \% \pm \\
1.7 \%\end{array}$ & 71 & 95 & 87 & 94 & 163 & 394 \\
\hline
\end{tabular}

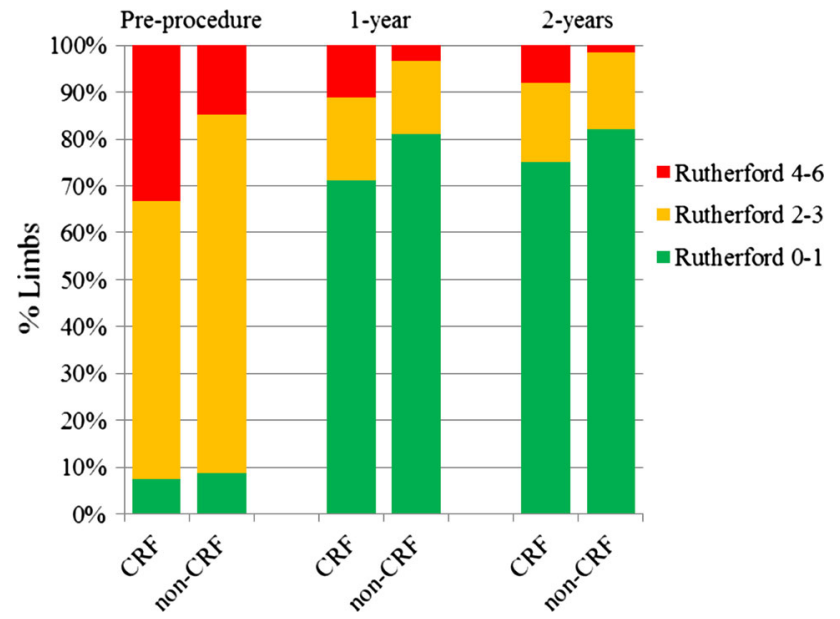

Fig. 5 Rutherford classification. Rutherford classification significantly improved for both groups from pre-procedure $(p<0.001)$. The incidence of CLI was reduced through 1 and 2 years in both groups of CRF patients with FP PAD appears to provide beneficial outcomes compared with those achievable with BMS and other standard endovascular interventions, even in patients with CLI.

Although the stent fracture rates were low in both the $\mathrm{CRF}$ and non-CRF groups, fractures were more frequent in the non-CRF group. The FP arteries are exposed to various forces such as compression, torsion, or elongation [26], and those forces are known to cause stent fractures [19]. Also, the overall length of the stented FP segment has been shown to be associated with an increased risk of stent fractures [27]. The reason for the lower incidence of stent fractures in the CRF group is unclear. Possible explanations may be related to the hard calcified arterial walls routinely present in CRF patients which may resist the various forces responsible for stent fracture and/or the fact that the CRF group was comprised of more CLI patients whose restricted level of physical activity and ambulation 
may limit untoward forces upon FP stents to a greater degree than in non-CLI patients. Further long-term evaluation may be needed to better understand this possible difference between CRF and non-CRF patients.

This study has several limitations. As described in the original study, it is difficult to distinguish between stent thrombosis and total occlusion caused by restenosis in FP PAD patients because there is no standardized classification for superficial femoral artery stent thrombosis. As such, we relied on site-reported determinations of stent thrombosis. Unfortunately, differences among sites and investigators may result in variable diagnosis.

Duplex ultrasonography for evaluating stent patency was performed only at sites where it was considered standard of care during follow-up surveillance. Consequently, approximately one-third of stented lesions were not evaluated for patency and are therefore not included in the calculation of patency. The present study collected information regarding the presence of renal failure (defined as eGFR $<60 \mathrm{~mL} / \mathrm{min} / 1.73 \mathrm{~m}^{2}$ and/or dialysis), but did not collect further information to distinguish if patients were receiving dialysis or experiencing severe CRF $\left(\mathrm{eGFR}<30 \mathrm{~mL} / \mathrm{min} / 1.73 \mathrm{~m}^{2}\right.$ ). It is known that patients with severe $\mathrm{CRF}$ or dialysis have a poorer prognosis including decreased limb salvage than patients with less severe renal failure [4]. More detailed categorization of CRF into subgroups using a standardized chronic kidney disease classification [28] may help better evaluate the full range of $\mathrm{CRF}$ patients and their response to various endovascular FP interventions.

\section{Conclusion}

This is a first comparative study of Zilver PTX between $\mathrm{CRF}$ and non-CRF groups. These results indicate that the DES placed in FP lesions of CRF patients is safe and effective with similar patency and TLR rates compared to patients without CRF.

Acknowledgements The authors thank Anthony O. Ragheb, Ph.D. and Sarah Boylen of Cook Research Incorporated, a contract research organization and Cook Group Company, for assistance with data analysis, figure preparation, and critical review of the manuscript.

Funding This study was sponsored by Cook Medical.

\section{Compliance with Ethical Standards}

Conflict of interest Dr. Yokoi has received speakers' fees from Cook Medical. Dr. Ohki has received research fees for clinical trials. Drs. O'Leary and Lottes and Mr. Saunders are paid employees of Cook Research Incorporated, a contract research organization and Cook Group Company. Dr. Dake is a member of the scientific advisory board for W.L. Gore and Associates and has received consulting fees from Cook Medical and Novate Medical. All other authors have reported that they have no conflicts relevant to the contents of this paper to disclose.

Ethical Approval and Informed Consent All procedures performed in studies involving human participants were in accordance with the ethical standards of the institutional and/or national research committee and with the 1964 Helsinki declaration and its later amendments or comparable ethical standards. For this type of study, informed consent processes were determined by each institution's ethical committee policy to specify whether informed consent was necessary or outcome data could be abstracted while protecting patient's rights without requiring individual patient consent.

Open Access This article is distributed under the terms of the Creative Commons Attribution 4.0 International License (http:// creativecommons.org/licenses/by/4.0/), which permits unrestricted use, distribution, and reproduction in any medium, provided you give appropriate credit to the original author(s) and the source, provide a link to the Creative Commons license, and indicate if changes were made.

\section{References}

1. Orimoto Y, Ohta T, Ishibashi H, Sugimoto I, Iwata H, Yamada T, et al. The prognosis of patients on hemodialysis with foot lesions. J Vasc Surg. 2013;58(5):1291-9. doi:10.1016/j.jvs.2013.05.027.

2. Nathan DP, Tang GL. The impact of chronic renal insufficiency on vascular surgery patient outcomes. Semin Vasc Surg. 2014;27(3-4):162-9. doi:10.1053/j.semvascsurg.2015.01.006.

3. Fallon JM, Goodney PP, Stone DH, Patel VI, Nolan BW, Kalish JA, et al. Outcomes of lower extremity revascularization among the hemodialysis-dependent. J Vasc Surg. 2015;62(5):1183-91. doi:10.1016/j.jvs.2015.06.203.

4. Patel VI, Mukhopadhyay S, Guest JM, Conrad MF, Watkins MT, Kwolek CJ, et al. Impact of severe chronic kidney disease on outcomes of infrainguinal peripheral arterial intervention. J Vasc Surg. 2014;59(2):368-75. doi:10.1016/j.jvs.2013.09.006.

5. Matsumi J, Tobita K, Shishido K, Mizuno S, Yamanaka F, Murakami M, et al. Comparison of long-term patency after endovascular therapy for superficial femoral artery occlusive disease between patients with and without hemodialysis. Catheter Cardiovasc Interv. 2016;87(6):1142-8. doi:10.1002/ccd.26359.

6. Meyer A, Lang W, Borowski M, Torsello G, Bisdas T, Collaborators C. In-hospital outcomes in patients with critical limb ischemia and end-stage renal disease after revascularization. J Vasc Surg. 2016;63(4):966-73. doi:10.1016/j.jvs.2015.10.009.

7. Dake MD, Ansel GM, Jaff MR, Ohki T, Saxon RR, Smouse HB, et al. Paclitaxel-eluting stents show superiority to balloon angioplasty and bare metal stents in femoropopliteal disease: Twelve-month Zilver PTX randomized study results. Circ Cardiovasc Interv. 2011;4(5):495-504. doi:10.1161/circinterven tions.111.962324.

8. Dake MD, Ansel GM, Jaff MR, Ohki T, Saxon RR, Smouse HB, et al. Sustained safety and effectiveness of paclitaxel-eluting stents for femoropopliteal lesions: 2-year follow-up from the Zilver PTX randomized and single-arm clinical studies. J Am Coll Cardiol. 2013;61(24):2417-27. doi:10.1016/j.jacc.2013.03. 034.

9. Dake MD, Ansel GM, Jaff MR, Ohki T, Saxon RR, Smouse HB, et al. Durable clinical effectiveness with paclitaxel-eluting stents in the femoropopliteal artery: 5-year results of the Zilver PTX 
randomized trial. Circulation. 2016;133(15):1472-83. doi:10. 1161/circulationaha.115.016900.

10. Ohki T, Yokoi H, Kichikawa K, Kimura T, Snyder SA, Ragheb AO, et al. Two-year analysis of the Japanese cohort from the Zilver PTX randomized controlled trial supports the validity of multinational clinical trials. J Endovasc Ther. 2014;21(5):644-53. doi:10.1583/ 14-4753.1.

11. Iida O, Takahara M, Soga Y, Nakano M, Yamauchi Y, Zen K, et al. 1-year results of the ZEPHYR registry (Zilver PTX for the femoral artery and proximal popliteal artery): predictors of restenosis. J Am Coll Cardiol Interv. 2015;8(8):1105-12. doi:10. 1016/j.jcin.2015.03.022.

12. Yokoi H, Ohki T, Kichikawa K, Nakamura M, Komori K, Nanto $\mathrm{S}$, et al. Zilver PTX post-market surveillance study of paclitaxeleluting stents for treating femoropopliteal artery disease in Japan: 12-month results. J Am Coll Cardiol Interv. 2016;9(3):271-7. doi:10.1016/j.jcin.2015.09.035.

13. Viener A, Aviram M, Better OS, Brook JG. Enhanced in vitro platelet aggregation in hemodialysis patients. Nephron. 1986;43(2): 139-43.

14. Notohamiprodjo M, Andrassy K, Bommer J, Ritz E. Dialysis membranes and coagulation system. Blood Purif. 1986;4(1-3): $130-41$.

15. Ishii H, Kumada Y, Toriyama T, Aoyama T, Takahashi H, Yamada S, et al. Cilostazol improves long-term patency after percutaneous transluminal angioplasty in hemodialysis patients with peripheral artery disease. Clin J Am Soc Nephrol. 2008; 3(4):1034-40. doi:10.2215/cjn.05761207.

16. Ihnat DM, Duong ST, Taylor ZC, Leon LR, Mills JL Sr, Goshima $\mathrm{KR}$, et al. Contemporary outcomes after superficial femoral artery angioplasty and stenting: the influence of TASC classification and runoff score. J Vasc Surg. 2008;47(5):967-74. doi:10.1016/j.jvs. 2007.12.050.

17. Bakken AM, Protack CD, Saad WE, Hart JP, Rhodes JM, Waldman DL, et al. Impact of chronic kidney disease on outcomes of superficial femoral artery endoluminal interventions. Ann Vasc Surg. 2009;23(5):560-8. doi:10.1016/j.avsg.2008.11. 010 .

18. Willenberg T, Baumann F, Eisenberger U, Baumgartner I, Do DD, Diehm N. Impact of renal insufficiency on clinical outcomes in patients with critical limb ischemia undergoing endovascular revascularization. J Vasc Surg. 2011;53(6):1589-97. doi:10.1016/ j.jvs.2011.01.062.

19. Kay M, Rogoveanu R, Hodson J, Tallowin S, Hopkins J, Duddy $\mathrm{M}$, et al. Factors affecting the results of superficial femoral artery stenting. Vasc Endovasc Surg. 2015;49(8):228-35. doi:10.1177/ 1538574415614405.

20. Simons JP, Goodney PP, Nolan BW, Cronenwett JL, Messina LM, Schanzer A, et al. Failure to achieve clinical improvement despite graft patency in patients undergoing infrainguinal lower extremity bypass for critical limb ischemia. J Vasc Surg. 2010;51(6):1419-24. doi:10.1016/j.jvs.2010.01.083.

21. Goodney PP, Nolan BW, Schanzer A, Eldrup-Jorgensen J, Bertges DJ, Stanley AC, et al. Factors associated with amputation or graft occlusion one year after lower extremity bypass in northern New England. Ann Vasc Surg. 2010;24(1):57-68. doi:10.1016/j.avsg.2009.06.015.

22. Yamamoto S, Hosaka A, Okamoto H, Shigematsu K, Miyata T, Watanabe T. Efficacy of revascularization for critical limb ischemia in patients with end-stage renal disease. Eur $\mathrm{J}$ Vasc Endovasc Surg. 2014;48(3):316-24. doi:10.1016/j.ejvs.2014.05. 019.

23. Kawamura Y, Ishii H, Aoyama T, Tanaka M, Takahashi H, Kumada $Y$, et al. Nitinol stenting improves primary patency of the superficial femoral artery after percutaneous transluminal angioplasty in hemodialysis patients: a propensity-matched analysis. J Vasc Surg. 2009;50(5):1057-62. doi:10.1016/j.jvs.2009. 07.017.

24. Ramdev P, Rayan SS, Sheahan M, Hamdan AD, Logerfo FW, Akbari CM, et al. A decade experience with infrainguinal revascularization in a dialysis-dependent patient population. J Vasc Surg. 2002;36(5):969-74.

25. Owens CD, Ho KJ, Kim S, Schanzer A, Lin J, Matros E, et al. Refinement of survival prediction in patients undergoing lower extremity bypass surgery: stratification by chronic kidney disease classification. J Vasc Surg. 2007;45(5):944-52. doi:10.1016/j.jvs. 2007.01.025.

26. Young MD, Streicher MC, Beck RJ, van den Bogert AJ, Tajaddini A, Davis BL. Simulation of lower limb axial arterial length change during locomotion. J Biomech. 2012;45(8):1485-90. doi:10.1016/j.jbiomech.2012.02.011.

27. Scheinert D, Scheinert S, Sax J, Piorkowski C, Braunlich S, Ulrich $\mathrm{M}$, et al. Prevalence and clinical impact of stent fractures after femoropopliteal stenting. J Am Coll Cardiol. 2005;45(2): 312-5. doi:10.1016/j.jacc.2004.11.026.

28. Goolsby MJ. National Kidney Foundation Guidelines for chronic kidney disease: evaluation, classification, and stratification. J Am Acad Nurse Pract. 2002;14(6):238-42. 